\title{
DAS diferentes CRISEs À PANDEMIA dA COVID 19
}

\author{
a Humanidade doente e o caminho de cura proposto \\ pelo Papa Francisco
}

\author{
Ms. Pe. Ari Antônio dos Reis* \\ Dr. Armando De Negri Filho ${ }^{\star \star}$ \\ DOI: https://doi.org/10.52451/teopraxis.v37i129.6 \\ Recebido: 04 de dezembro de 2018 | Aprovado: 29 de março de 2019
}

Resumo: $O$ presente artigo apresenta uma reflexão sobre diferentes crises da humanidade que, segundo o Papa Francisco, se constituem em uma única crise de origem sócio ambiental e que explicitam a doença da humanidade. Apresenta também a proposta do Pontífice, através de gestos, iniciativas e escritos, com os possíveis caminhos de superação dessa grande crise, ou, enfermidade, a partir de uma nova perspectiva de relacionamento social tendo o ser humano como prioridade.

Palavras-chave: Crises. Humanidade. Economia. Sociedade. Doença. Integração. Cuidado. Meio ambiente. Educação. Vida.

\section{Introdução}

Neste artigo pretende-se fazer uma análise desta situação, momentaneamente marcada pela pandemia da Covid 19 que,

* Presbítero da Arquidiocese de Passo Fundo/RS. Graduado em Filosofia pela Universidade de Passo Fundo e Teologia pela Itepa Faculdades de Passo Fundo. Mestre em Teologia Pastoral pela Pontifícia Faculdade Nossa Senhora da Assunção. Professor da Itepa Faculdades, nas áreas de Metodologia e Prática Pastoral, Teologia da Revelação, Ecumenismo e Diálogo Inter religioso: E-mail: reis.abt@gmail.com

* Graduado em Medicina pela Universidade Federal do Rio Grande do Sul. Mestrado em Epidemiologia pela Universidade Federal de Pelotas (1995). Mestrado Profissional em Saúde Pública - Saúde Global e Diplomacia da Saúde pela Escola Nacional de Saúde Pública Sergio Arouca (ENSP/Fiocruz). Master em Gestão Clínica e Coordenação Médica pela Escuela Nacional de Sanidad / Instituto Carlos III de Madrid Espanha e Universidad de Educación a la Distancia da Espanha. E-mail: armandodenegri@yahoo.com 
por sua vez, mostrou a marca da desigualdade estrutural na sociedade brasileira e pode ser lida como um estágio no processo de enfermidade da humanidade. Este artigo tem um viés teológico-pastoral. Certamente poder-se-ia enfocar a temática adotando outras referências, mas intuiu-se por bem fazer a abordagem teológica e pastoral com aportes em outras áreas do conhecimento.

Serão abordadas, em um primeiro momento, algumas crises que assolam a humanidade e sua influência na vida humana, dentre elas a crise da Covid 19, assim como as iniciativas e dificuldades no enfrentamento desta pandemia, sobretudo, quando os processos de articulação mundial foram relativizados em nome de posturas políticas fechadas e equivocadas. Como referência teológico-pastoral apresentam-se as manifestações públicas do Papa Francisco denunciando os condicionantes sociopolíticos dessas crises e as proposições desse Eminente Prelado na perspectiva de superação desse aflitivo contexto humano-social.

\section{As diferentes crises da humanidade}

No documento conclusivo e gestado durante a V Conferência do Episcopado Latino Americano e Caribenho ocorrido na cidade de Aparecida - SP, durante o ano de 2007, ao abordar a realidade como desafio ao agir evangelizador da Igreja no continente, o Colegiado Episcopal selou o termo “mudança de época”. Segundo o documento, essa expressão aponta para as grandes mudanças que afetam profundamente a vida humana, têm alcance global e com diferenças e matizes afetam o mundo inteiro (cf. DAp 34).

$\mathrm{Na}$ Assembleia dos Bispos do Brasil (2019) o termo foi enfocado de uma forma mais precisa. O documento orientativo para a atividade evangelizadora da Igreja previsto para o quadriênio 2019-2023 afirma que "os fundamentos últimos para 
a compreensão da realidade se tornam frágeis a ponto de suscitar perplexidade e insegurança” (CNBB, 2019, p.43). As duas leituras da realidade feitas num prazo de 12 anos revelam um processo histórico de dificuldades da humanidade e das diferentes instituições, dentre elas a Igreja Católica, de compreenderem e abordarem o fenômeno. Certamente outras igrejas cristãs e tradições religiosas percebem estas dificuldades com alguma mudança de nuance. O Documento de Aparecida explicitou as diferentes faces desta transição de mudanças tão profundas $^{1}$.

A reflexão sobre as mudanças se aprofundou e hoje se fala em crises da humanidade. Dependendo da análise mencionamse diferentes crises. O Papa Francisco tem se manifestado afirmando que estamos passando por uma única crise, a crise sócio-ambiental, segundo o argumento que a abordagem ecológica compreende também a abordagem social que deve integrar a justiça nos debates sobre o meio ambiente, ouvindo o clamor da terra e o clamor dos pobres (cf. LS 49). Optamos por tratar quatro crises como oportunidade de explicitarmos um pouco melhor cada uma: econômica, social, democrática e ambiental, acrescentando a crise da Covid 19 que interage com as demais.

\subsection{Crise econômica}

As crises no capitalismo são cíclicas. Contudo não significam o enfraquecimento do capitalismo, mas sua reconfiguração em outros parâmetros e, em muitos casos, gerando mais situações de pobreza e desigualdade social. A partir de 2008, iniciando nos Estados Unidos, começou um processo novo de crises que chegou aos países europeus. Não há

1 Para aprofundar: CELAM. Documento de Aparecida: Texto conclusivo da V Conferência do Episcopado Latino-Americano e do Caribe. Brasília: Ed. CNBB, 2007. 
como esquecer as constantes notícias sobre o grande contingente de desempregados, sobretudo na Espanha e Grécia. Cabe destacar as sucessivas tentativas de solução, preservando o mercado, visto que os nomes escolhidos para chefia dos governos serem pessoas do mercado e não escolha da população.

No Brasil, a partir de 2014, ocorreu processo semelhante com uma roupagem própria, especialmente pela falta de disposição do Governo Dilma em garantir as exigências do mercado financeiro. Esta crise culminou com o impedimento da presidente e a ascensão de Temer, com a tarefa de "acalmar" o mercado às custas do freio nos investimentos sociais e as diferentes reformas para potencializar o projeto capitalista financeiro.

Reitera-se que as crises contribuem, em muitos casos, para o revigoramento do projeto capitalista e não existe um interesse ético para salvar os que ficam no caminho. Eles não importam. Não são significantes. Para o capitalismo financeiro os pobres são descartáveis como denuncia o Papa Francisco:

Não se trata simplesmente do fenômeno da exploração e opressão, mas de uma realidade nova: com a exclusão, fere-se, na própria raiz, a pertença à sociedade onde se vive, pois quem vive nas favelas, na periferia ou sem poder já não está nela, mas fora. Os excluídos não são explorados, mas resíduos, sobras (EG 53).

$\mathrm{Na}$ verdade, interessam ao mercado os que oferecem algo ou os que se apresentam como consumidores. No Brasil, esta lógica se arquiteta com formas escandalosas. No verso da medalha, é um país extremamente avançado em alguns setores e, deficitário em outros. Seu perfil flutua ao critério dos interesses econômicos em jogo. 


\subsection{Crise social}

Esta é uma crise permanente no Brasil inscrita, ainda hoje, em sua estrutura histórica, injusta e desigual. Perdeu-se num horizonte longínquo o projeto de nação, submerso pela constituição de um Estado a serviço de uma minoria que foi assumindo diferentes roupagens ao longo dos séculos. No projeto Brasil a Casa Grande é o sujeito de direitos, cabendo os deveres à Senzala. O histórico de pobreza e miséria permanente no Brasil não tem sofrido transformações a partir de iniciativas do Estado. Alguma mudança ocorrida decorreu da pressão popular. Apresentaram-se alguns paliativos reformistas em alguns momentos da história, contudo sem um abalo maior na estrutura desigual. As diferentes representações do poder se articulam pela sua manutenção, usufruindo dos bens produzidos e apoiadas em um Estado erigido para proteger alguns e resistir às reinvindicações da maioria. Neste modelo de relação o Brasil continuará gerando empobrecidos e miseráveis e continuará tratando esta parcela da população como ameaça às "pessoas de bem".

No momento em que a Senzala reivindica seus direitos a pretensa ordem social fica abalada. Demanda desta relação a ideia de que problema social é caso de polícia. Esta noção equivocada permanece. As crises, sejam socioeconômicas ou culturais não chegam a mexer nas estruturas societárias em seu fundamento capitalista. Mais do que isso, é inegável que não existe uma reta intencionalidade de subvertê-las. Basta ver a aprovação do teto de gastos durante o governo Temer.

\subsection{Crise democrática}

As diferentes semanas sociais brasileiras, promovidas pela Conferência Nacional dos Bispos do Brasil desde 1991 têm apontado para a insuficiência da democracia representativa no

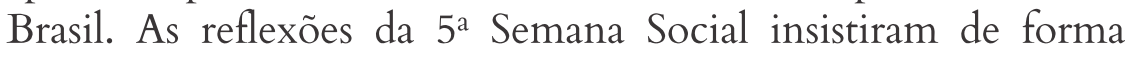


direta na necessidade de potencialização da democracia com reais mecanismos de participação popular nas decisões quanto às suas vidas.

Contudo no contexto atual este mesmo modelo, mesmo insuficiente, está sendo rompido a partir das suas próprias estruturas. No Brasil e no mundo, governantes eleitos democraticamente tratam de romper a própria democracia. O rompimento democrático acontece, portanto, nos parâmetros da própria democracia. Não se desconhece o papel do capitalismo financeiro na estruturação ou no abalo de estruturas de governo. A via eleitoral deixa de ser democrática quando o poder financeiro garante mandatos. Soma-se ao financiamento de interesses antidemocráticos, a recente força das fakenews. A possibilidade da população de refletir e decidir sobre temas importantes a ela relacionados fica cada vez mais complexa e distante.

\subsection{Crise ambiental}

Possivelmente esta crise seja tão antiga como as crises do capitalismo, contudo tem se revelado com mais evidência nas últimas décadas. Começou no momento em que a humanidade se colocou em contraposição ao mundo criado ${ }^{2}$ diante do qual recebeu a tarefa do cultivo e guarda (cf. Gn 2,15).

A relação passou a ser de tentativa de domínio para se tirar o que se considerava necessário, unicamente, para a sobrevivência humana. O princípio antropocêntrico, colocou no centro da relação o ser humano e suas necessidades. Demanda daí uma grande crise, sobretudo porque a super exploração da natureza potencializada na modernidade volta-se à satisfação dos

2 O conceito de mundo criado ou criação é extraído da tradição bíblica segundo o texto do Gênesis, capítulos 1 e 2 que apresenta a narrativa da criação segundo a cultura judaico cristã. Os diferentes povos africanos também falam da terra e da humanidade como fruto do desejo criador da divindade. 
interesses de uma minoria. Mesmo que esta crise tenha sido ainda negada, especialmente por alguns chefes de governo, compreende-se o fenômeno das mudanças climáticas devido ao aquecimento global como um alerta inequívoco do esgotamento da Terra. Popularmente tem se dito que a Terra está "febril".

Na Encíclica Laudato Sí, publicada em maio de 2015, o Papa Francisco critica a via única de pretenso desenvolvimento humano e rápidos processos de mudanças que implicam na vida do planeta. Os recursos naturais são esgotados em prazos muito curtos.

Embora a mudança faça parte da dinâmica dos sistemas complexos, a velocidade que hoje lhes impõem as ações humanas, contrasta com a lentidão natural da evolução biológica" (LS 18). Segundo ele é uma mudança que fragiliza e não fortalece porque a "mudança é algo desejável, mas torna-se preocupante quando se transforma em deterioração do mundo e da qualidade de vida de grande parte da humanidade" (LS 18).

A Terra está esgotada em seus recursos, afetando seus processos naturais. $\mathrm{O}$ mais grave, insiste-se que estes bens naturais são destinados a uns poucos. Tudo é célere sem preocupação com o amanhã.

\subsection{A crise da Covid 19 e a crise das instituições}

A pandemia da Covid 19 alastrou-se pelo mundo, atacando a todos com maior ou menor intensidade. As mais diferentes nações se envolveram em ações de prevenção. Chamou atenção a forma como esta crise foi enfrentada pelos diferentes governantes. Fez parte da orquestração política em torno da crise, a relativização e até desautorização das orientações da Organização Mundial de Saúde quanto às medidas para impedir a rápida disseminação do vírus, como também as formas de tratamento. 
No caso do Brasil a primeira reação foi de negação da gravidade do problema e a forma como o governo federal articulou o enfrentamento fez que a situação se agravasse. Como a pandemia foi objeto de disputa ideológica formou-se uma grande confusão de narrativas, deixando a população desorientada. $O$ fato de a pandemia ter interferido na economia pela necessidade de reclusão e consequente influência nas trocas econômicas, a atuação do governo brasileiro foi, primeiramente, voltada para salvaguardar o mercado financeiro.

Apesar da relutância optou pelo auxílio emergencial para a população que ficou sem acesso a uma renda mínima. Contudo, mesmo com a pandemia ceifando vidas o projeto neoliberal avançou na sua estruturação. Cito como exemplo a aprovação da Lei de Privatização do Saneamento Básico. Paralelo a isso cita-se a crescente destruição da Floresta Amazônica que acontece de uma forma tão brutal ao ponto de gerar reações inclusive dentro do mercado, visto que se faz necessário, ao menos uma faceta de preocupação ambiental para ganhar a simpatia dos consumidores. Uma necropolítica ganha corpo, na medida que revela uma não preocupação do atual chefe governo brasileiro que, reiteradamente, tem demostrado indiferença em relação às vidas perdidas por causa da pandemia.

\section{A desordem mundial e a penalização dos pobres}

As crises acima descritas, mesmo que de forma sucinta, e possivelmente já refletidas em outros momentos pelos leitores, mostram que por trás de uma pretensa ordem mundial de orientação neoliberal forjada pelas sequentes crises históricas, sendo a mais recente iniciada em 2008, na verdade, é uma grande desordem.

Contudo, nesta desordem, o capitalismo se refaz e se revitaliza. Faz isso às custas da fragilização dos povos, morte da população empobrecida e da destruição do mundo criado. 
Invertem-se as prioridades. $\mathrm{O}$ mercado financeiro é colocado acima da vida humana. Segundo este princípio equivocado é necessário garantir a vitalidade do mercado, mesmo que se percam vidas. Segue-se a lógica de que é o mercado que importa, as vidas nem tanto. Esse processo de ampla desigualdade foi criticado pelo Papa Paulo VI na Encíclica Populorum Progressio, na época, também chamando a atenção para a desigualdade entre os povos.

Dito e reconhecido isto, não resta dúvida alguma de que o equipamento existente está longe de bastar para se opor à dura realidade da economia moderna. Entregue a si mesmo, o seu mecanismo arrasta o mundo, mais para a agravação do que para a atenuação da disparidade dos níveis de vida: os povos ricos gozam de um crescimento rápido, enquanto os pobres se desenvolvem lentamente. O desequilíbrio aumenta: alguns produzem em excesso gêneros alimentícios, que faltam cruelmente a outros, vendo estes últimos tornarem-se incertas as suas exportações (PP 8).

Alguns teólogos que refletem o diálogo entre teologia e economia, dentre os quais Hugo Assmann, Franz Hinkelammert e Jung Mo Sung ${ }^{3}$, apontam a divinização do mercado como fundamento das exigências de sacrifícios, no caso dos humanos e da natureza. O mercado necessita deles para permanecer em pé. É a idolatria que se mantém graças aos sacríficos humanos e da natureza. Insistimos que a ordem do mercado financeiro se faz às custas da desordem humana e do mundo criado. Enquanto não for revista esta prioridade que feita cultura, a inversão destruidora de vidas permanecerá. $\mathrm{O}$ Papa Paulo VI já lembrava da necessidade de rever as prioridades quanto à noção de desenvolvimento.

3 Para aprofundar: Hugo ASSMANN e Franz J. HINKELLAMMERT. A idolatria do mercado: ensaio sobre economia e teologia, Petrópolis: Vozes 1989. Também a obra de Jung Mo SUNG. Teologia e economia: repensando a teologia da libertação e utopias. Petrópolis: Vozes, 1994. 
O desenvolvimento não se reduz a um simples crescimento econômico. Para ser autêntico, deve ser integral, quer dizer, promover todos os homens e o homem todo, como justa e vincadamente sublinhou um eminente especialista: não aceitamos que o econômico se separe do humano; nem o desenvolvimento, das civilizações em que ele se incluiu. O que conta para nós, é o homem, cada homem, cada grupo de homens, até se chegar à humanidade inteira (PP 14).

No instante em que economia se divorcia da responsabilidade pela manutenção da vida humana, que é a razão da sua existência, ela perde o sentido ético e o significado para a sociedade. Sobre este rompimento sublinha-se a colocação do Papa Francisco na Exortação Evangelii Gaudium: não é possível que morte por enregelamento de um idoso sem abrigo não seja notícia, enquanto o é a descida de dois pontos na Bolsa (EG 53).

Este sinal de ordem-desordem se estrutura a partir da inversão de valores visto que a economia não está a serviço da humanidade, mas adquiriu um fim em si mesma. A proposição de um encontro com jovens sobre a economia de Francisco e Clara, tema abordado em seguida, processo que está mobilizando grupos do mundo todo, visa contribuir nesta reflexão necessária.

\section{Pontificado de Francisco como um permanente alerta profético sobre as crises}

Os Papas foram líderes com papel significativo para além da esfera cristã católica. Esta afirmação não significa flerte com a cristandade, mas a compreensão do papel de um pontífice como líder de uma coletividade que, a partir de suas posições, influencia grandemente os destinos da humanidade, apesar dos contrapontos próprios da diversidade sócio-política mundial. Corroborando com esta afirmação faz-se memória do papel do 
Papa João Paulo II no enfrentamento do socialismo real do leste Europeu. O Papa Francisco, eleito em 2013, tem assumido este papel de líder mundial com grande responsabilidade, sobretudo em um contexto de carência de lideranças carismáticas para a humanidade.

Foi eleito a partir da tensão e esgotamento de um modelo de pontificado que forçava uma aparente coesão interna, representado por João Paulo II e continuado por Bento XVI, com algumas diferenciações. O fato da renúncia de Bento XVI, gesto de extrema humildade, revelou a sua consciência de que não teria forças para operar as mudanças necessárias à Igreja naqueles períodos de grande turbulência. Seguiu-se a eleição do Papa Francisco. Ao ser apresentado para a multidão reunida na Praça São Pedro afirmou que "foram buscar ele lá do fim do mundo para ser Papa".

É possível interpretar esta afirmação na perspectiva de que se procurou outro modelo de condução para a Igreja Católica e o Cardeal Mario Jorge Bergoglio fora o escolhido. Foi novidade também o nome escolhido, Francisco, com todo o significado místico e de vida pobre que o santo de Assis inspirava. No decorrer do seu pontificado Francisco tem mostrado que tem uma proposta para a Igreja e para o mundo. Sugeriu uma Igreja "em saída e pobre para os pobres". E provocou a humanidade superar a globalização da indiferença. Ressalta-se que o Papa Francisco é herdeiro do projeto eclesiológico latino-americano demarcado sobretudo através dos encontros do episcopado desde 1968 com a Conferência de Medellín ${ }^{4}$.

Descreveremos brevemente algumas manifestações do Papa voltadas à superação da desordem mundial e sua consequente enfermidade.

4 Segunda Conferência do Episcopado Latino-americano ocorrida na cidade de Medellín, Colômbia, após o Concílio Vaticano II. 


\subsection{Ilha de Lampedusa: crítica à globalização da indiferença}

A visita do Papa Francisco em julho de 2013 à Ilha de Lampedusa, localidade no extremo sul da Itália, procurada por migrantes do norte da África, teve um caráter simbólico profundo. Afirma-se que este gesto foi uma encíclica não escrita. Lá, o Papa condenou o descaso das autoridades europeias diante do fenômeno das migrações, certamente, um problema muito complexo.

Ao celebrar a eucaristia em um altar montado com restos de embarcações naufragadas, Papa Francisco denunciou, com veemência, a globalização da indiferença e a necessidade de um compromisso de uns pelos outros. Disse:

A cultura do bem-estar, que nos leva a pensar em nós mesmos, torna-nos insensíveis aos gritos dos outros, faz-nos viver como se fôssemos bolhas de sabão: estas são bonitas, mas não são nada, são pura ilusão do fútil, do provisório. Esta cultura do bem-estar leva à indiferença a respeito dos outros; antes, leva à globalização da indiferença. Neste mundo da globalização, caímos na globalização da indiferença. Habituamo-nos ao sofrimento do outro, não nos diz respeito, não nos interessa, não é responsabilidade nossa! ${ }^{5}$

O desinteresse pelos sofredores se constitui uma cultura marcada pelo isolamento social, porque o ser humano não vê o outro como um irmão. Faz-se indiferente ao seu sofrimento. $\mathrm{O}$ Pontífice propõe outro caminho, a solidariedade humana. Na Exortação Evangelli Gaudium explicita o sentido da solidariedade, nestes tempos, o antídoto contra a globalização da indiferença:

Embora um pouco desgastada e, por vezes, até mal interpretada, a palavra solidariedade significa muito mais do que alguns atos esporádicos de generosidade; supõe a criação duma nova

5 http://www.ihu.unisinos.br/noticias/521786-qadao-onde-estas-caim-onde-estao-teu-irmao-o-discurso-de-francisco-em-lampedusa 
mentalidade que pense em termos de comunidade, de prioridade da vida de todos sobre a apropriação dos bens por parte de alguns (EG 188).

Esta solidariedade vai se configurando e penetrando no dia a dia dos povos e tem a finalidade de transformar as estruturas sociais sustentadoras da indiferença:

Estas convicções e práticas de solidariedade, quando se fazem carne, abrem caminho a outras transformações estruturais e tornam-nas possíveis. Uma mudança nas estruturas, sem se gerar novas convicções e atitudes, fará com que essas mesmas estruturas, mais cedo ou mais tarde, se tornem corruptas, pesadas e ineficazes (EG 189).

É necessário potencializar a solidariedade e descobrir o seu sentido transformador mais profundo como caminho da superação da omissão e da indiferença que matam. Também redescobrir o seu sentido profético, porque como proposta política é um sinal profético frente à economia do mercado, embasada no individualismo e no egoísmo e a indiferença pelas diferentes formas de vida.

\subsection{Visita à Organização das Nações Unidas - ONU}

Esta visita carrega a simbologia do diálogo da Igreja com o mundo através das nações. O Papa é considerado um Chefe de Estado, portanto com assento na ONU. Outros Papas também já haviam visitado a sede em Nova York. A visita de Francisco fez parte das comemorações dos setenta anos da ONU. Na ocasião discursou na abertura da Cúpula do Desenvolvimento Sustentável e reafirmou alguns princípios que marcam o seu pontificado, com destaque ao combate à exclusão econômica e à destruição do meio ambiente, segundo ele, enraizados na ambição desmedida e na sede de poder. Disse: 
O abuso e a destruição do meio ambiente aparecem associados, simultaneamente, com um processo ininterrupto de exclusão. $\mathrm{Na}$ verdade, uma ambição egoísta e ilimitada de poder e bem-estar material leva tanto a abusar dos meios materiais disponíveis como a excluir os fracos e os menos hábeis, seja pelo facto de terem habilidades diferentes (deficientes), seja porque lhes faltam conhecimentos e instrumentos técnicos adequados ou possuem uma capacidade insuficiente de decisão política. A exclusão econômica e social é uma negação total da fraternidade humana e um atentado gravíssimo aos direitos humanos e ao ambiente. Os mais pobres são aqueles que mais sofrem esses ataques por um triplo e grave motivo: são descartados pela sociedade, ao mesmo tempo são obrigados a viver de desperdícios, e devem injustamente sofrer as consequências do abuso do ambiente. Estes fenômenos constituem, hoje, a cultura do descarte tão difundida e inconscientemente consolidada ${ }^{6}$.

Assumiu a responsabilidade de colaborar na construção de outras formas de relação entre os homens e com o mundo criado, dentre estas a agenda para o desenvolvimento sustentável:

O caráter dramático de toda esta situação de exclusão e desigualdade, com as suas consequências claras, leva-me, juntamente com todo o povo cristão e muitos outros, a tomar consciência também da minha grave responsabilidade a este respeito, pelo que levanto a minha voz, em conjunto com a de todos aqueles que aspiram por soluções urgentes e eficazes ${ }^{7}$.

Não deixou de destacar que, mais do que acordos de cúpulas e ações burocráticas, as mudanças devem chegar aos homens e mulheres necessitados:

6 http://www.vatican.va/content/francesco/pt/speeches/2015/september/documents/ papa-francesco_20150925_onu-visita.html

7 http://www.vatican.va/content/francesco/pt/speeches/2015/september/documents/ papa-francesco_20150925_onu-visita.html 
É preciso não perder de vista, em momento algum, que a ação política e econômica só é eficaz quando é concebida como uma atividade prudencial, guiada por um conceito perene de justiça e que tem sempre presente que, antes e para além de planos e programas, existem mulheres e homens concretos, iguais aos governantes, que vivem, lutam e sofrem e que muitas vezes se vêem obrigados a viver miseravelmente, privados de qualquer direito $^{8}$.

Estes deverão ser protagonistas dos seus destinos e jamais serem vítimas da imposição de algum projeto:

o desenvolvimento humano integral e o pleno exercício da dignidade humana não podem ser impostos; devem ser construídos e realizados por cada um, por cada família, em comunhão com os outros seres humanos e num relacionamento correto com todos os ambientes onde se desenvolve a sociabilidade humana - amigos, comunidades, aldeias e vilas, escolas, empresas e sindicatos, províncias, países, etc ${ }^{9}$.

\subsection{Encíclica Laudato Sí: sobre o cuidado com a casa comum}

O alerta sobre a crise ambiental e a necessidade da mudança das nossas relações com o planeta foi descrito de uma forma precisa com a Encíclica Laudato Sí. Propõe o diálogo a partir de uma causa que deveria ser comum a toda a humanidade, o planeta Terra, ou a mãe-irmã terra, como ele mesmo descreve (LS 1). Parte de uma constatação: esta irmã clama contra o mal que lhe provocamos por causa do uso irresponsável e do abuso dos bens que Deus nela colocou (LS 2). Faz um apelo a toda humanidade: o urgente desafio de proteger a nossa casa comum inclui a preocupação de unir toda a família humana na busca de

8 http://www.vatican.va/content/francesco/pt/speeches/2015/september/documents/ papa-francesco_20150925_onu-visita.html

9 http://www.vatican.va/content/francesco/pt/speeches/2015/september/documents/ papa-francesco_20150925_onu-visita.html 
um desenvolvimento sustentável e integral, pois sabemos que as coisas podem mudar (LS 13).

Apresenta uma proposta como caminho de superação do mal causado à casa comum, ameaçando inclusive o futuro das próximas gerações. Propõe a ecologia integral, ou seja, um outro estilo de vida em vista do bem comum e que inclua claramente as dimensões humanas e sociais, porque uma verdadeira abordagem ecológica sempre se torna uma abordagem social que deve integrar a justiça nos debates sobre o meio ambiente para ouvir tanto o clamor da terra como o clamor dos pobres (LS 49).

Sugere superação do paradigma tecnocrático devido a sua limitação e sustentação de uma economia que não constrói, mas que destrói a casa comum e destrói a vida humana. Sobre isso afirma:

Podemos afirmar que, na origem de muitas dificuldades do mundo atual, está principalmente a tendência sempre consciente, de elaborar metodologia e os objetivos da tecnociência segundo um paradigma de compreensão que condiciona a vida das pessoas e o funcionamento da sociedade. Os efeitos da aplicação deste modelo a toda a realidade, humana e social, constatam-se na degradação do meio ambiente, mas isso é apenas um sinal do reducionismo que afeta a vida humana e a sociedade em todas as dimensões (LS 107).

Este desvio será superado através da opção pela ecologia integral, como uma forma de conjugar as questões humanas, ambientais e econômicas tendo como horizonte a busca do bem comum.

\subsection{A denúncia da enfermidade humana}

No dia 27 de março, quando a Itália e demais países da Europa enfrentavam o sofrimento pela pandemia, o Papa Francisco se manifestou ao mundo. Chamou atenção o cenário 
desta manifestação. Era final de tarde e caia uma garoa fina. $\mathrm{O}$ Papa subiu sozinho ao parlatório tendo diante de si a Praça vazia.

Aquele cenário e a homilia do Papa foram marcantes. Ali ele explicitou que a humanidade já estava doente e que a Covid 19 era a explicitação cabal desta enfermidade. Naquele final de tarde disse o Papa diante da constatação da grande fragilidade humana:

A tempestade desmascara a nossa vulnerabilidade e deixa a descoberto as falsas e supérfluas seguranças com que construímos os nossos programas, os nossos projetos, os nossos hábitos e prioridades. Mostra-nos como deixamos adormecido e abandonado aquilo que nutre, sustenta e dá força à nossa vida e à nossa comunidade ${ }^{10}$.

Chamou a atenção aos equívocos cometidos pela humanidade:

$\mathrm{Na}$ nossa avidez de lucro, deixamo-nos absorver pelas coisas e transtornar pela pressa. Não nos detivemos perante os teus apelos, não despertamos face a guerras e injustiças planetárias, não ouvimos o grito dos pobres e do nosso planeta gravemente enfermo. Avançamos, destemidos, pensando que continuaríamos sempre saudáveis num mundo doente. Agora nós, sentindo-nos em mar agitado, imploramos-Te: Acorda, Senhor ${ }^{11}$

É possível superar a enfermidade da humanidade. Como?

10 Vaticannews.va/pt/papa/news/2020-03/papa-francisco-homilia-oracao-bencaourbe-et-orbi-27-marco.html

11 Vaticannews.va/pt/papa/news/2020-03/papa-francisco-homilia-oracao-bencaourbe-et-orbi-27-marco.html 


\section{Os possíveis caminhos para superar a crise a partir do viés teológico-pastoral}

As críticas sugerem caminhos. Os tantos documentos publicados pelo Papa Francisco sugerem caminhos para a superação da enfermidade humana. Nem sempre o enfrentamento é um processo fácil. Sem dúvida alguma a Exortação Evangelii Gaudium, sobre a evangelização e a Encíclica Laudato Sí sobre a questão ambiental apontam caminhos. Estas manifestações se reforçam com outras proposições que tem a grave missão de contribuir para a superação das enfermidades da humanidade.

Em dois encontros de representantes do Movimento Popular com o Papa Francisco, primeiramente em Roma (2014) e depois em Santa Cruz de la Sierra (Bolívia-2015), foram tratados temas fundamentais voltados à sobrevivência dos homens e mulheres empobrecidos: terra, teto e trabalho. Terra para cultivar, no caso dos agricultores; casa para que as famílias sejam abrigadas com dignidade; trabalho que permita ao ser humano, pelo esforço próprio e criativo, realizar-se como pessoa. São realidades estruturantes da vida humana, dimensões da vida que não podem ficar submissas às forças do capital, justamente pelo fato deste colocar o lucro acima de tudo. Segundo o Papa Francisco são direitos sagrados que enfocam a centralidade da pessoa em plena consonância com a Doutrina Social da Igreja ${ }^{12}$.

Em uma interpretação da potência desses três Ts, projetados na Sexta Semana Social Brasileira da CNBB, argumentamos seu sentido ao considerar:

- a Terra como Bem Comum e balizador de um Cuidado com Nossa Casa Comum, mas também da construção de uma Economia Social e Solidária a serviço do conjunto da Sociedade;

12 Os discursos do Papa Francisco nos dois encontros foram publicados pelas Edições CNBB. Coleção Sendas. Brasília: Edições CNBB, 2015. 
- de um Teto capaz de representar todo o Sistema de Proteções Sociais e Econômicas que devem caracterizar uma verdadeira Democracia, desconstruindo o discurso que naturaliza e legaliza a Pobreza, na realidade $o$ empobrecimento das pessoas e dos povos;

- de um Trabalho que reconheça o protagonismo humano sem discriminações na construção e usufruto do Bem Comum e que distribua a riqueza produzida em uma dinâmica equilibrada com os Direitos Humanos e os Direitos da Natureza, opondo-se ao predomínio do capital sobre o trabalho humano.

Em maio de 2019 Francisco convidou os jovens para discutir a economia, encontro primeiramente agendado para março de 2020. Segundo ele um evento que:

Permita encontrar-me com quantos estão a formar-se e começam a estudar e a pôr em prática uma economia diferente, que faz viver e não mata, inclui e não exclui, humaniza e não desumaniza, cuida da criação e não a devasta. Um acontecimento que nos ajude a estar unidos, a conhecer-nos uns aos outros, e que nos leve a estabelecer um "pacto" para mudar a economia atual e atribuir uma alma à economia de amanhã ${ }^{13}$.

O Papa está preocupado com a economia. Quer refletir sobre o tema junto com pessoas com capacidade de imprimir novos horizontes para a economia porque a forma como está sendo gerida não gera vida, mas morte. É uma economia que mata (EG 53). Para Francisco desponta a necessidade de exercitar um modelo econômico novo, fruto de uma cultura da comunhão, baseado na fraternidade e na equidade.

Em sintonia com a reflexão sobre a economia propõe-se a reflexão sobre a educação. Ao pronunciar-se no encontro "Educação: O Pacto Global", promovido pela Pontifícia

13 https://www.vaticannews.va/pt/vaticano/news/2020-02/editorial-economiafrancisco-construir-novos-caminhos-assis.html 
Academia das Ciências Sociais em fevereiro deste ano, afirmou que "é necessário unir esforços para alcançar uma aliança educacional ampla a fim de formar pessoas maduras, capazes de reconstruir o tecido relacional e criar uma humanidade mais fraterna". A proposição de debates no âmbito da economia e da educação estão na esteira das outras proposições do Papa.

É importante que se compreenda as falas de Francisco como o convite para se discutir os rumos da humanidade que precisa ser curada. O fermento foi lançado e está levedando a massa.

\section{Concluindo}

Este texto resultou da opção de refletir sobre as tantas crises que tem marcado a trajetória humana, marcadamente as mais recentes. Na perspectiva do mercado financeiro a crise não abala, mas o revitaliza e reforça mesmo que gerando destruição e mortes. O processo de crise se agravou com a pandemia da Covid 19. Esta pandemia em si é muito grave, pelo inusitado da sua disseminação e pelas dificuldades no enfrentamento, além de explicitar de forma mais grave as nossas carências.

Tem sido um alento para a humanidade as atitudes do Papa Francisco. Ele não tem hesitado em propor um caminho para a Igreja e para o mundo através dos gestos e escritos. Que nos ajude a construir um novo caminho.

\section{Referências Bibliográficas}

ASSMANN Hugo e HINKELLAMERT Franz J. A idolatria do mercado: ensaio sobre economia e teologia. Petrópolis: Vozes, 1989.

CELAM. Documento de Aparecida: Texto conclusivo da V Conferência do Episcopado Latino-Americano e do Caribe. Brasília: Ed. CNBB, 2007.

CNBB. Diretrizes Gerais da Ação Evangelizadora da Igreja no Brasil 20192023. Brasília: Ed. CNBB, 2019.

FRANCISCO, PAPA. Exortação Apostólica Evangelii Gaudium: sobre o anúncio do evangelho no mundo atual. Brasília: Ed. CNBB, 2014 
. Encíclica Lautato Sí. Brasília: Ed. CNBB, 2015.

. Benção et urbe et orbe. Vaticannews.va/pt/papa/news/2020-03/papafrancisco-homilia-oracao-bencao-urbe-et-orbi-27-marco.html. Acesso em 21 de agosto de 2020.

. Discurso do Papa Francisco no I Encontro Mundial dos Movimentos Populares. Coleção Sendas. Brasília. Ed. CNBB, 2015.

. Discurso do Papa Francisco no II Encontro Mundial dos Movimentos Populares. Coleção Sendas. Brasília. Ed. CNBB, 2015.

. Discurso por ocasião da visita à Sede da ONU.

http://www.vatican.va/content/francesco/pt/speeches/2015/september/docu ments/papa-francesco_20150925_onu-visita.html. Acesso em 20 de agosto de 2020.

. Homilia por ocasião da visita à Ilha de Lampedusa.

http://www.ihu.unisinos.br/noticias/521786-qadao-onde-estas-caim-ondeesta-o-teu-irmao-o-discurso-de-francisco-em-lampedusa. Acesso em 20 de agosto de 2020.

. https://www.vaticannews.va/pt/vaticano/news/2020-02/editorialeconomia-francisco-construir-novos-caminhos-assis.html. Acesso em 21 de agosto de 2020.

PAULO VI, PAPA. Populorum Progressio: sobre o desenvolvimento dos povos. Disponível em:http://www.vatican.va/content/paulvi/pt/encyclicals/documents/hf_p-vi_enc_26031967_populorum.html. Acesso em 21 de agosto de 2020.

SUNG Jung Mo. Teologia e economia: repensando a teologia da libertação e utopias. Petrópolis: Vozes, 1994. 